\title{
Explanatory Variables Associated with Campylobacter and Escherichia coli Concentrations on Broiler Chicken Carcasses during Processing in Two Slaughterhouses
}

\author{
EWA PACHOLEWICZ, ${ }^{1,2 *}$ ARNO SWART, ${ }^{3}$ JAAP A. WAGENAAR,${ }^{4,5,6}$ LEN J. A. LIPMAN, ${ }^{1}$ AND ARIE H. HAVELAAR ${ }^{1,7}$ \\ ${ }^{1}$ Division Veterinary Public Health, Institute for Risk Assessment Sciences, and ${ }^{4}$ Department of Infectious Diseases and Immunology, Faculty of Veterinary \\ Medicine, Utrecht University, Utrecht, 3508 TD, The Netherlands; ${ }^{2}$ MEYN Food Processing Technology B. V., Oostzaan, 1511 MA, The Netherlands; \\ ${ }^{3}$ Centre for Infectious Disease Control, National Institute for Public Health and the Environment, Bilthoven, 3720 BA, The Netherlands; ${ }^{5}$ Central Veterinary \\ Institute of Wageningen UR, Lelystad, The Netherlands; ${ }^{6} \mathrm{WHO}$-Collaborating Center for Campylobacter/OIE Reference Laboratory for \\ Campylobacteriosis, Utrecht, The Netherlands; and ${ }^{7}$ Emerging Pathogens Institute and Department of Animal Sciences, University of Florida, Gainesville,
} Florida 32610-0009, USA

MS 16-064: Received 10 February 2016/Accepted 6 June 2016

\begin{abstract}
This study aimed at identifying explanatory variables that were associated with Campylobacter and Escherichia coli concentrations throughout processing in two commercial broiler slaughterhouses. Quantative data on Campylobacter and E. coli along the processing line were collected. Moreover, information on batch characteristics, slaughterhouse practices, process performance, and environmental variables was collected through questionnaires, observations, and measurements, resulting in data on 19 potential explanatory variables. Analysis was conducted separately in each slaughterhouse to identify which variables were related to changes in concentrations of Campylobacter and E. coli during the processing steps: scalding, defeathering, evisceration, and chilling. Associations with explanatory variables were different in the slaughterhouses studied. In the first slaughterhouse, there was only one significant association: poorer uniformity of the weight of carcasses within a batch with less decrease in $E$. coli concentrations after defeathering. In the second slaughterhouse, significant statistical associations were found with variables, including age, uniformity, average weight of carcasses, Campylobacter concentrations in excreta and ceca, and E. coli concentrations in excreta. Bacterial concentrations in excreta and ceca were found to be the most prominent variables, because they were associated with concentration on carcasses at various processing points. Although the slaughterhouses produced specific products and had different batch characteristics and processing parameters, the effect of the significant variables was not always the same for each slaughterhouse. Therefore, each slaughterhouse needs to determine its particular relevant measures for hygiene control and process management. This identification could be supported by monitoring changes in bacterial concentrations during processing in individual slaughterhouses. In addition, the possibility that management and food handling practices in slaughterhouses contribute to the differences in bacterial contamination between slaughterhouses needs further investigation.
\end{abstract}

Key words: Poultry; Processing hygiene; Risk factors

Campylobacteriosis is a zoonosis caused by thermotolerant Campylobacter spp. The most frequent symptom in patients is self-limiting gastroenteritis, but severe complications, such as reactive arthritis and neurological disorders, including Guillain-Barré syndrome, may also occur and even result in death (13). Campylobacteriosis is the most frequently reported zoonosis in the European Union, with 214,779 cases of campylobacteriosis reported in 2013 (13). The main source of infection in humans is the poultry reservoir (11). The control of Campylobacter throughout the poultry supply chain, including at slaughter, is crucial to reduce the number of human cases of campylobacteriosis. It is expected that reducing levels on carcasses at slaughter will reduce the number of cases of campylobacteriosis in humans $(11,26)$.

\footnotetext{
* Author for correspondence. Tel: +31 30253 2347; Fax: +31 30253

2365, E-mail: e.pacholewicz@uu.nl.
}

The levels of Campylobacter on carcasses after chilling differ, depending on the origin of batch and the slaughterhouse where the batches were processed $(2,10,22,28)$. To determine potential causes of the differences, the changes in Campylobacter concentration through broiler processing steps were investigated (22). Processing steps, such as defeathering and evisceration, were identified as crucial for control, because they may lead to an increase in bacterial concentrations on carcasses. The effect of processing steps, including defeathering, evisceration, scalding, and chilling on increase or decrease in bacterial concentrations, differ between slaughterhouses (22). The reasons for this have not yet been fully identified or quantified.

Currently, factors that influence Campylobacter colonization in batches on farms have been identified $(6,18)$. In the slaughterhouse, factors influencing Campylobacter prevalence after chilling have been identified $(15,16)$, but little is known 
of factors that influence changes (increases or decreases) in Campylobacter concentrations on carcasses during broiler processing. Identifying such factors should enable the implementation of control measures to reduce the Campylobacter concentration on carcasses at the end of slaughter and thus the number of human infections. In addition, determining whether similar factors influence Escherichia coli and Campylobacter concentration on carcasses would support the control of hygienic performance during processing based on $E$. coli, as proposed by the Panel of Biological Hazards of the European Food Safety Authority (12). The correlation between Campylobacter and E. coli concentrations on broiler chicken carcasses has been investigated in various studies, but results were contradictory $(4,9,22,27)$. However, our previous study (22) found that concentrations of both Campylobacter and $E$. coli changed in a similar way at most steps along the processing line. Therefore, E. coli could be used as an indicator of processing hygiene to identify the processing steps that are critical for control (22). The objective of this study was to identify variables associated with Campylobacter and E. coli concentrations on carcasses during processing in two slaughterhouses previously studied (22).

\section{MATERIALS AND METHODS}

Experimental design. The investigations were conducted in two commercial broiler chicken slaughterhouses, characterized in Table 1. The study took place between June and October of 2012 and 2013. Batches were considered as the analytical unit, with a batch being a group of chickens raised in one house (11). In total, 21 batches (Table 1), positive for Campylobacter on the farm, were sampled, as explained in detail in our previous study (22). In short: in slaughterhouse 1 , there were 11 batches tested, whereas in slaughterhouse 2, 10 batches were tested (Table 1). On the farm, the batches were tested for presence of Campylobacter (22). Only positive batches were investigated at slaughter.

Collection of samples. Whole carcass rinse samples were collected after five processing steps: bleeding, scalding, defeathering, evisceration, and chilling. For each location and batch, between three and eight samples were collected, as described previously (22). In total, 677 rinse samples were collected (22).

Additional samples were collected, including excreta from carcasses, after scalding. For this, the abdomen of the carcass was pressed to obtain at least $1 \mathrm{~g}$ of sample from the vent. In total, 136 excreta samples were collected. These samples provided data on bacterial concentration in material that may leak during defeathering. To confirm positivity and investigate concentrations of Campylobacter in the sampled batches, eight complete intestinal tracts from 12 batches ( $\mathrm{J}$ to $\mathrm{U}$ ) were collected at the veterinary inspection station, which yielded 96 cecal samples.

For batches A to G, 24 additional postscalding carcasses were collected (three per batch A to D and four per batch E to G) and defeathered manually. Carcasses were removed from the processing line and hung on shackles standing next to the processing line. Feathers were removed by hand and collected in a sterile bag and weighted. This procedure took approximately $5 \mathrm{~min}$. The person who defeathered the carcasses wore disposable gloves and changed them between each carcass. Afterwards, each defeathered carcass was placed in a plastic bag and rinsed with $500 \mathrm{ml}$ of peptone saline (see details in the following section). The rinse samples were used to compare the bacterial concentrations between manually and mechanically defeathered carcasses.
Samples from the defeathering environment were collected during processing of batches A to G. Forty water samples (approximately $100 \mathrm{ml}$ ) and 40 feather samples (approximately $25 \mathrm{~g}$ ) were collected from the first and last defeathering machine. In slaughterhouse 1, there were three machines, and slaughterhouse 2 had four.

Sample preparation and enumeration. Whole carcass rinse samples were prepared, as described previously (22). In summary, the carcasses were placed in sterile plastic bags, and $500 \mathrm{ml}$ of peptone saline was added and rinsed by shaking for $60 \mathrm{~s}$. Afterwards, $100 \mathrm{ml}$ was collected in a sterile plastic jar and stored at $3^{\circ} \mathrm{C}\left( \pm 2^{\circ} \mathrm{C}\right)$ until laboratory analysis. The intestines were transported to the laboratory, where at least $1 \mathrm{~g}$ of cecal content per carcass was collected. The cecum was dipped in $70 \%$ ethanol, then it was cut with a sterile scalpel, and the cecal material was collected in a sterile plastic jar. Afterwards, the sample was 1:10 diluted in Butterfield's buffer (3M, Zoeterwoude, The Netherlands) and homogenized by shaking the jars. The samples from excreta were handled in a similar way as the cecal samples. Further serial 1:10 dilutions of all samples were made in Butterfield's buffer. Campylobacter was enumerated by using CampyFood agar (bioMérieux, Inc., Marcy l'Etoile, France), following ISO 10272-2 (1). E. coli was enumerated by using 3M Petrifilms (3M, Zoeterwoude, The Netherlands).

Explanatory variables. The 19 explanatory variables collected for each batch relate to batch characteristics, slaughterhouse practices, process performance, and environment (Table 2). The list of variables was chosen based on a literature review and interviews with experts in broiler processing microbiology. Variables related to food handlers were evaluated in the following study (20). Batch-related variables were measured at farms and slaughterhouses via a questionnaire filled in by farmers and quality managers. Variables related to slaughterhouse practices and environment were obtained from measurements made during the sampling of each batch. Process performance variables were collected through observation of both the defeathering and evisceration processes. Defeathering performance was assessed from the number of feathers remaining on parts of the carcass, such as wings, hocks, and abdomen and breakages (of wings and hocks) on the 20 carcasses observed from each batch. The remaining feathers on the 20 carcasses were evaluated by scoring each assessed part of the carcass (scores 1 to 4). Score 1 was assigned when all feathers were removed, score 2 when the number of remaining feathers was below 5 on the assessed part, score 3 when the number was between 5 and 10 , and score 4 when the number was above 10 . The scores from all parts were summed per carcass and averaged per 20 carcasses in each batch to obtain an overall batch score. Higher average scores indicated insufficient defeathering and potentially inadequate setting of the equipment. To evaluate breakages on wings and hocks, parts of the carcass (wings and feet) were assigned 0 (not broken) and 1 (broken). For each batch, scores from 20 carcasses were averaged to obtain an overall score for breakages after defeathering. Higher average scores indicated more frequent breakage that may have been caused by an extensively tight setting of defeathering equipment. It is expected that when the two banks of the machine are very close to each other, there is pressure on the carcasses; therefore, bone breakage and fecal leakage might occur.

Evisceration performance was assessed by counting carcasses with visible fecal contamination after evisceration during $1 \mathrm{~min}$ of processing. The results were presented as a percentage of carcasses with visible fecal contamination, and higher scores indicated a potentially poor setting of the evisceration equipment. Lack of adjustment of evisceration machines to the size of processed carcasses might cause the rupture of viscera (24). Uniformity of a batch 
TABLE 1. Characteristics of the two slaughterhouses

\begin{tabular}{|c|c|c|}
\hline & Slaughterhouse 1 & Slaughterhouse 2 \\
\hline No. of lines & 1 & 2 \\
\hline Line speed (birds/h) & 8,500 & 7,200 \\
\hline No. of shifts & 2 & 2 \\
\hline $\begin{array}{l}\text { Capacity (no. of broilers } \\
\text { slaughtered per day) }\end{array}$ & 130,000 & 240,000 \\
\hline Production, fresh; frozen & $95 \%$ fresh; $5 \%$ frozen & $70 \%$ fresh; $30 \%$ frozen \\
\hline Unloading & Tilting system & Belt system \\
\hline Live hanging & Carousel system & Carousel system \\
\hline Bleeding time (s) & 180 & 185 \\
\hline Stunning & Water bath high frequency & Water bath high frequency \\
\hline Killing & Left side and frontal cut & Frontal cut \\
\hline Immersion scalding & Fresh product (epidermis on) & Fresh product (epidermis on) \\
\hline Temp & $51.5-52.8^{\circ} \mathrm{C}$ & $52.8-53.5^{\circ} \mathrm{C}$ \\
\hline Time & $3 \min$ & $\begin{array}{l}2.5 \mathrm{~min} \\
\text { Frozen product (epidermis off) } \\
54-57.2^{\circ} \mathrm{C} \\
2.5 \mathrm{~min}\end{array}$ \\
\hline \multicolumn{3}{|l|}{ Defeathering } \\
\hline Time (s) & 37 & 46 \\
\hline Water consumption & 0.5 liter/carcass & 0.8 liter/carcass \\
\hline $\begin{array}{l}\text { Evisceration (key machines) } \\
\text { Chilling }\end{array}$ & $\begin{array}{l}\text { Vent cutter, opener, eviscerator, spraying nozzles } \\
\text { Immersion tanks } \\
\text { Air chilling: } 105 \mathrm{~min}\end{array}$ & $\begin{array}{l}\text { Vent cutter, opener, eviscerator, spraying cabinet } \\
\text { Immersion tanks } \\
\text { Air chilling (carcasses with epidermis): } 80 \text { min } \\
\text { Air + spray chilling (carcasses without epidermis): } \\
\quad 80 \text { min }\end{array}$ \\
\hline Batch identification & $\mathrm{A}, \mathrm{B}, \mathrm{C}, \mathrm{I}, \mathrm{K}, \mathrm{L}, \mathrm{N}, \mathrm{O}, \mathrm{Q}, \mathrm{R}, \mathrm{U}$ & $\mathrm{D}, \mathrm{E}, \mathrm{F}, \mathrm{G}, \mathrm{H}, \mathrm{J}, \mathrm{M}, \mathrm{P}, \mathrm{S}, \mathrm{T}$ \\
\hline
\end{tabular}

indicates the homogeneity of the weight of broilers within a batch. This was calculated on the basis of the coefficient of variation, which is the ratio of the standard deviation and the average of the weight after chilling (5). This coefficient was presented as a percentage.

Statistical analysis. Analyses were performed by using the $\mathrm{R}$ software (Version 3.2.0, R Development Core Team, Vienna, Austria). First, variables were selected as potentially affecting Campylobacter and E. coli concentrations for a particular processing step, based on a literature review and consultations with experts in the field of poultry processing hygiene. Pearson's correlation coefficient $(r)$ of the bacterial counts and explanatory variables were computed for these variables (results not shown), and variables with $|r|>0.7$ were considered to be statistically associated. For each set of the associated variables, one was choosen based on expert opinion for further analysis, and the rest were disregarded. Calculation of the correlation was a preliminary step to exclude the variables that could confound the model. Correlation does not necessarily indicate a technological causal relation between the variables; it was performed to inform the following data analysis. The selected variables were analyzed based on the following model to identify a significant association between explanatory variables and the impact of the processing step on both Campylobacter and $E$. coli concentrations (Table 3). The Bonferroni-Holm correction (14) was applied to address the multiple comparisons of selected variables in the model. Two significance levels were considered: $P$ $=0.05$ and a less strict level of $P=0.1$. The following equation describes the bacterial concentrations on carcasses, including selected variables, during the processing steps studied:

$$
\begin{aligned}
\text { Concentration }= & b_{0}+\beta_{0}+\beta_{1} \text { explanatory variable } \\
& +\beta_{2} \text { processed } \\
& +\beta_{3} \text { explanatory variable } \times \text { processed }+\varepsilon
\end{aligned}
$$

In the model "concentration" is the Campylobacter or E. coli concentration in the whole carcass rinse sample. The intercept $b_{0}+$ $\beta_{0}$ (bacterial concentrations during the processing steps at zero value of the explanatory variable) varied between batches. The "explanatory variable" is a variable from the list, as described in Table 3. "Processed" is a variable indicating whether the concentrations were measured before (processed $=0$ ), or after (processed $=1$ ) a particular step. A significant interaction of the processed and explanatory variable indicates that the explanatory variable affected the change in concentration during processing. This form of analysis allowed using each data point, even though the samples before and after processing steps were not paired. The analyses were computed separately for Campylobacter and E. coli in each slaughterhouse. A comparison of the contamination levels in the rinse samples obtained from mechanically and manually defeathered carcasses for Campylobacter and E. coli was done by the two-sample Wilcoxon test.

To investigate differences in the impact of defeathering between slaughterhouses and bacterial species, the concentrations in samples collected before (in the carcass rinse after scalding), during (in excreta, water, and feathers), and after defeathering (in the carcass rinse after defeathering) were compared for both Campylobacter and E. coli. The concentrations of the bacteria in the samples were converted taking a carcass as the analytical unit and presenting the results as log CFU per carcass. Thus, 
TABLE 2. Descriptive statistics of the explanatory variables of the batches tested

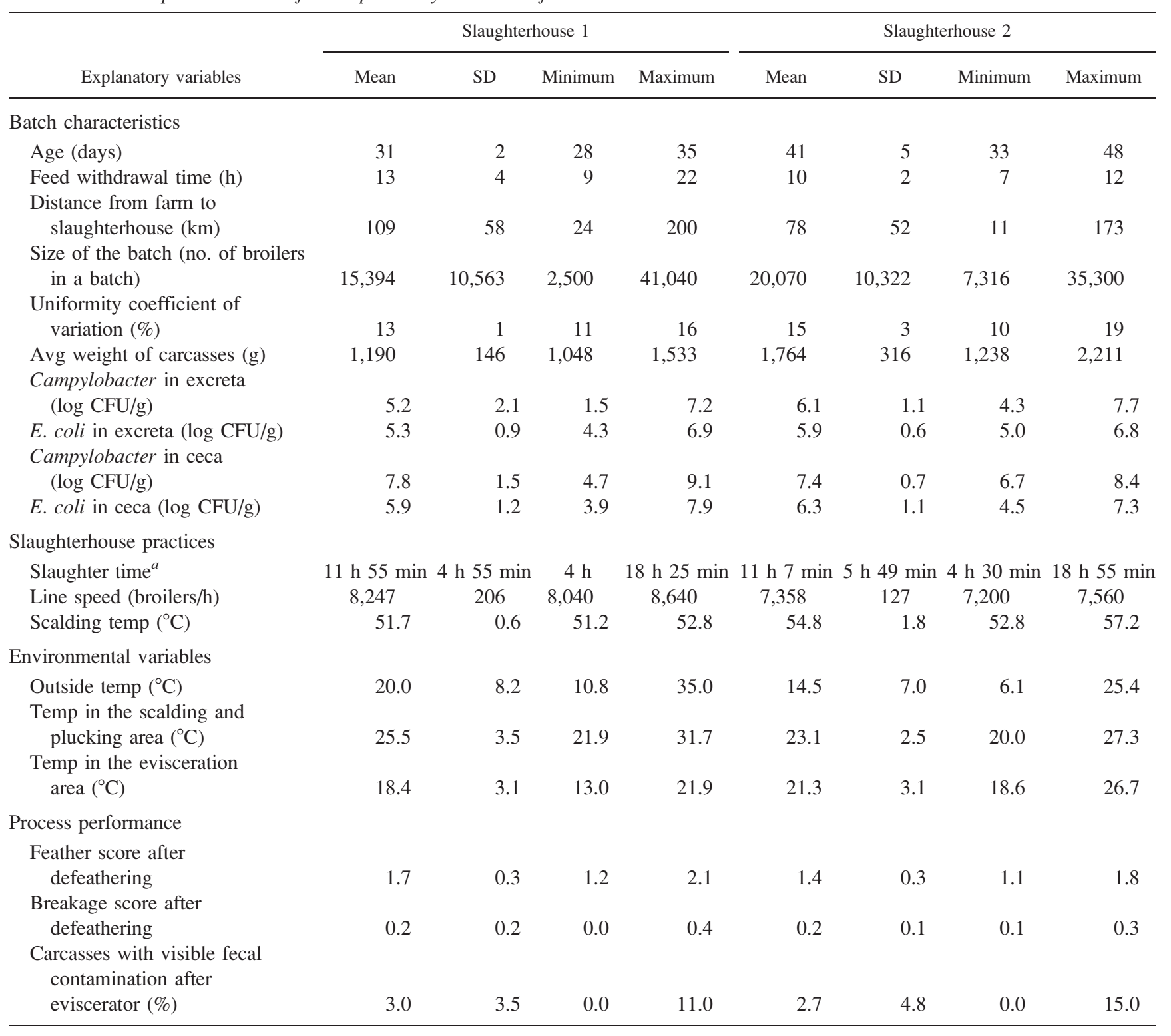

${ }^{a}$ Number of hours and minutes after midnight.

concentrations in the carcass rinse were calculated per $500 \mathrm{ml}$ of peptone saline. Concentrations in $1 \mathrm{~g}$ of excreta were converted to the number in the total weight of excreta pressed from the vent of each samped carcass. Concentrations in $1 \mathrm{~g}$ of feathers were converted to the numbers present in the mean weight of feathers present on the entire carcass estimated based on the experiment on manual defeathering. Concentrations in $1 \mathrm{ml}$ of water taken under the defeathering machines were converted to total numbers per 500 $\mathrm{ml}$ in slaughterhouse 1 and per $800 \mathrm{ml}$ in slaughterhouse 2. These are the volumes, reported to be used per carcass by each slaughterhouse during processing (Table 1). The bacterial concentrations in these samples (before, during, and after defeathering) were compared by analysis of variance (ANOVA) and the post hoc Tukey honestly significant difference test.

\section{RESULTS}

Variables associated with changes in Campylobacter and $\boldsymbol{E}$. coli concentration. The correlated variables in one slaughterhouse were not always correlated in the other slaughterhouse (results not shown). Of 19 explanatory variables selected for the study, three variables were significantly associated with changes in Campylobacter concentrations during the processing steps tested in slaughterhouse 2, with none in slaughterhouse 1. There was one variable associated with $E$. coli concentrations in slaughterhouse 1 and four in slaughterhouse 2 (Table 3 ).

In slaughterhouse 1 , poorer uniformity (coefficient of variation in weight of carcasses within a batch, expressed in percentage) of the batch was associated with a lower decrease in $E$. coli concentrations during defeathering by $0.14 \log$ per percentage point. In contrast, in slaughterhouse 2 , the poorer uniformity was associated with a greater decrease in $E$. coli concentrations during defeathering by 0.15 log per percentage point.

Age was associated with a smaller decrease in $E$. coli concentrations during scalding in slaughterhouse 2 by 0.07 log per day of age. Age was poorly related to the 
TABLE 3. Explanatory variables associated with Campylobacter and E. coli concentrations on carcasses at several processing steps in two slaughterhouses ${ }^{a}$

\begin{tabular}{|c|c|c|c|c|}
\hline \multirow[b]{3}{*}{ Explanatory variables } & \multicolumn{4}{|c|}{ Slaughterhouse 1} \\
\hline & \multicolumn{4}{|c|}{ Campylobacter } \\
\hline & Scalding & Defeathering & Evisceration & Chilling \\
\hline \multicolumn{5}{|l|}{ Batch characteristics } \\
\hline Age (days) & -0.11 & 0.05 & -0.08 & 0.1 \\
\hline Feed withdrawal time (h) & -0.02 & & -0.02 & 0.05 \\
\hline Distance from farm to slaughterhouse $(\mathrm{km})$ & & & -0.003 & \\
\hline Size of the batch (no. of broilers in a batch) & 0.00001 & -0.00002 & -0.00001 & 0.00001 \\
\hline Uniformity coefficient of variation (\%) & 0.25 & -0.17 & 0.01 & \\
\hline Avg weight of carcasses (g) & & & -0.001 & \\
\hline Campylobacter in excreta $(\log \mathrm{CFU} / \mathrm{g})$ & -0.55 & 0.66 & -0.53 & \\
\hline E. coli in excreta $(\log \mathrm{CFU} / \mathrm{g})$ & & & & \\
\hline Campylobacter in ceca $(\log \mathrm{CFU} / \mathrm{g})$ & & & & 0.22 \\
\hline E. coli in ceca $(\log \mathrm{CFU} / \mathrm{g})$ & & & & \\
\hline \multicolumn{5}{|l|}{ Slaughterhouse practices } \\
\hline Slaughter time (h) & 0.06 & -0.04 & & -0.01 \\
\hline Line speed (broilers/h) & & 0.001 & & \\
\hline Scalding temp $\left({ }^{\circ} \mathrm{C}\right)$ & -0.72 & 0.71 & -0.45 & 0.06 \\
\hline \multicolumn{5}{|l|}{ Environmental variables } \\
\hline Outside temp $\left({ }^{\circ} \mathrm{C}\right)$ & & & & \\
\hline Temp in the scalding and plucking area $\left({ }^{\circ} \mathrm{C}\right)$ & 0.09 & -0.08 & 0.03 & \\
\hline Temp in the evisceration area $\left({ }^{\circ} \mathrm{C}\right)$ & & & & \\
\hline \multicolumn{5}{|l|}{ Process performance } \\
\hline Feathers score after defeathering & & -0.34 & & \\
\hline Breakages score after defeathering & & & & \\
\hline Carcasses with visible fecal contamination after eviscerator (\%) & & & -0.02 & \\
\hline
\end{tabular}

${ }^{a}$ Numbers in the cells indicate the estimate $\beta_{3}$ in the model, as described in equation 1 . The estimates in bold indicate the explanatory variable that significantly contributed to change in concentration during processing (below $P=0.05$ indicated by $* *$ and below $P=0.1$ indicated by *). Empty cells indicate that the particular variable was either not assigned by experts for analysis at a particular processing step or was correlated with other variables.

concentrations of both Campylobacter and E. coli in excreta and in cecal content (Fig. 1). Within the measured range, each $\log$ increase in Campylobacter concentration in excreta in slaughterhouse 2 corresponded to a higher decrease during chilling of $0.35 \mathrm{log}$. In cecal contents, each log increase in Campylobacter concentration was associated with a higher increase during defeathering of $0.67 \mathrm{log}$. Each E. coli $\log$ increase in the excreta in slaughterhouse 2 was associated with a lower decrease during defeathering of $0.61 \mathrm{log}$.

The weight of the carcasses in slaughterhouse 2 was significantly associated with an increase in Campylobacter concentrations on carcasses after evisceration, by $0.002 \mathrm{log} / \mathrm{g}$.

Higher defeathering efficiency, indicated by the number of remaining feathers (presented as a score), was associated with a higher decrease in $E$. coli concentrations during defeathering in slaughterhouse 2 .

Defeathering in two slaughterhouses. Campylobacter concentrations in carcass rinse samples did not differ between manually and mechanically defeathered carcasses in slaughterhouse $1(P=0.23)$ or in slaughterhouse $2(P=$ 0.84; Fig. 2). Concentrations of $E$. coli did not differ significantly in slaughterhouse $2(P=0.58)$. In slaughter- house 1 , however, $E$. coli concentrations in mechanically defeathered carcasses were significantly lower $(P=0.002)$ by $1.4 \log$.

The Campylobacter and E. coli concentrations on carcasses before, during, and after defeathering are presented in Figure 3, which shows that when higher concentrations of bacteria were found on the excreta than in carcass rinse samples before defeathering, the concentrations in the carcass rinse after defeathering generally increased and vice versa (Table 4). In addition, examination of feathers and water from the defeathering machines showed that high numbers of both Campylobacter and E. coli were removed during defeathering (Fig. 3).

\section{DISCUSSION}

Trends in Campylobacter and E. coli concentrations along the processing line differed between slaughterhouses and were either regular (slaughterhouse 1) or variable (slaughterhouse 2) between tested batches (22). This difference can be potentially explained by the differences in the batch characteristics and processing parameters applied in each slaughterhouse (Tables 1 and 2). Also, variables associated with changes in both Campylobacter 
TABLE 3. Extended

\begin{tabular}{|c|c|c|c|c|c|c|c|c|c|c|c|}
\hline \multicolumn{4}{|c|}{ Slaughterhouse 1} & \multicolumn{8}{|c|}{ Slaughterhouse 2} \\
\hline \multicolumn{4}{|c|}{ E. coli } & \multicolumn{4}{|c|}{ Campylobacter } & \multicolumn{4}{|c|}{ E. coli } \\
\hline Scalding & Defeathering & Evisceration & Chilling & Scalding & Defeathering & Evisceration & Chilling & Scalding & Defeathering & Evisceration & Chilling \\
\hline $\begin{array}{l}-0.06 \\
-0.03\end{array}$ & -0.03 & $\begin{array}{c}0.03 \\
-0.02 \\
-0.002\end{array}$ & $\begin{array}{l}-0.05 \\
-0.03\end{array}$ & 0.03 & & & -0.01 & $0.07 * *$ & & & 0.06 \\
\hline 0.00001 & 0.000002 & -0.00001 & -0.000004 & -0.00002 & -0.00001 & 0.00002 & -0.00002 & -0.000004 & -0.00001 & 0.00001 & -0.00002 \\
\hline 0.02 & $0.14 *$ & $\begin{array}{r}-0.15 \\
0.001\end{array}$ & 0.02 & -0.06 & $\begin{array}{l}-0.05 \\
-0.001\end{array}$ & $\begin{array}{l}-0.002 \\
\mathbf{0 . 0 0 2} * * *\end{array}$ & & 0.08 & $\begin{array}{l}-\mathbf{0 . 1 5} * * \\
-0.001\end{array}$ & $\begin{array}{c}0.01 \\
-0.0004\end{array}$ & -0.003 \\
\hline-0.19 & -0.07 & 0.16 & -0.005 & 0.07 & $\begin{array}{r}-0.1 \\
\mathbf{0 . 6 7 *}\end{array}$ & 0.26 & $\begin{array}{l}-\mathbf{0 . 3 5} * * \\
-0.65\end{array}$ & -0.25 & $0.61 * *$ & 0.13 & -0.09 \\
\hline 0.03 & -0.09 & 0.08 & 0.01 & & & & & -0.14 & 0.09 & 0.25 & -0.28 \\
\hline-0.01 & $\begin{array}{l}-0.004 \\
-0.0005\end{array}$ & 0.01 & & -0.001 & -0.001 & $\begin{array}{l}-0.03 \\
0.0005\end{array}$ & -0.001 & 0.001 & -0.001 & $\begin{array}{c}-0.01 \\
0.001\end{array}$ & $\begin{array}{c}0.03 \\
-0.001\end{array}$ \\
\hline-0.08 & -0.41 & 0.5 & -0.23 & 0.02 & 0.17 & & & -0.13 & 0.15 & & \\
\hline \multirow[t]{3}{*}{0.04} & 0.04 & -0.07 & & -0.09 & 0.08 & -0.01 & & & 0.06 & & \\
\hline & 0.11 & & & & & & & & $-1.3 * *$ & & \\
\hline & & 0.005 & & & -1.28 & -0.02 & & & & 0.01 & \\
\hline
\end{tabular}

and $E$. coli concentrations on carcasses through the broiler processing differed between the slaughterhouses. More variables were found in slaughterhouse 2 . This could be related to higher variability in processed batches (e.g., age) and parameters (e.g., scalding temperature) in slaughterhouse 2 than in slaughterhouse 1. The differences observed between slaughterhouses demonstrate that risks vary between slaughterhouses. Although hygiene control should be based on hazard analysis and critical control point in each slaughterhouse, the importance of the critical control points might differ between slaughterhouses. Control measures should, thus, be determined individually by each slaughterhouse, which points to the need for monitoring bacterial concentrations at various processing points in each slaughterhouse. Monitoring changes in E. coli concentration during processing would be more cost-effective and less timeconsuming than monitoring pathogens. The critical processing steps determined by using $E$. coli would be valid for multiple hazards, because $E$. coli shares sufficient similarities with Campylobacter and extended-spectrum- $\beta$-lactamase and AmpC-producing E. coli $(21,22)$. This would also enable monitoring and evaluation of the effectiveness of process hygiene to be done with the help of process hygiene criteria based on E. coli, recommended by the European Food Safety Authority (12).

In our study, most of the variables associated with Campylobacter concentrations were different from the variables associated with $E$. coli concentrations on carcasses
(Table 3). However, for both bacteria, associations were observed between their concentrations on carcasses and in the excreta or cecal content at various processing steps. These findings are in line with previously reported associations between Campylobacter concentrations in cecal contents and on the carcasses after defeathering and evisceration $(23,25)$. Based on our findings, the reduction during chilling was greater in the case of batches with a higher Campylobacter concentration in the excreta. The reason for this association is unclear. According to Reich et al. (23), a positive correlation was observed between Campylobacter concentrations in cecal contents and on carcasses, while our results showed the opposite. A recent study on air chilling in a laboratory-scale setting demonstrated that Campylobacter reduction was not observed on carcasses carrying a concentration above $3 \mathrm{log} \mathrm{CFU} / \mathrm{g}$ of tested chicken carcass parts (24).

The presence of carcasses with visible fecal contamination during broiler processing, e.g., after evisceration (Table 2), is not uncommon $(8,25)$. The percentage of carcasses with visible fecal contamination (Table 2) can be explained, for example, by explanatory variables (this study) and by food handlers' compliance with process control procedures (20). Leakage of fecal and cecal material during processing is recognized as an important source of crosscontamination of the carcasses $(3,7,17)$. Our results show that when the concentration of bacteria in the excreta was higher than on the outside of the carcass, there was a greater 
FIGURE 1. Poor relationship between age (in days) of the sampled batches and concentrations of both Campylobacter and E. coli (log CFU per carcass) in excreta (collected after scalding) and cecal contents in slaughterhouses 1 and 2.

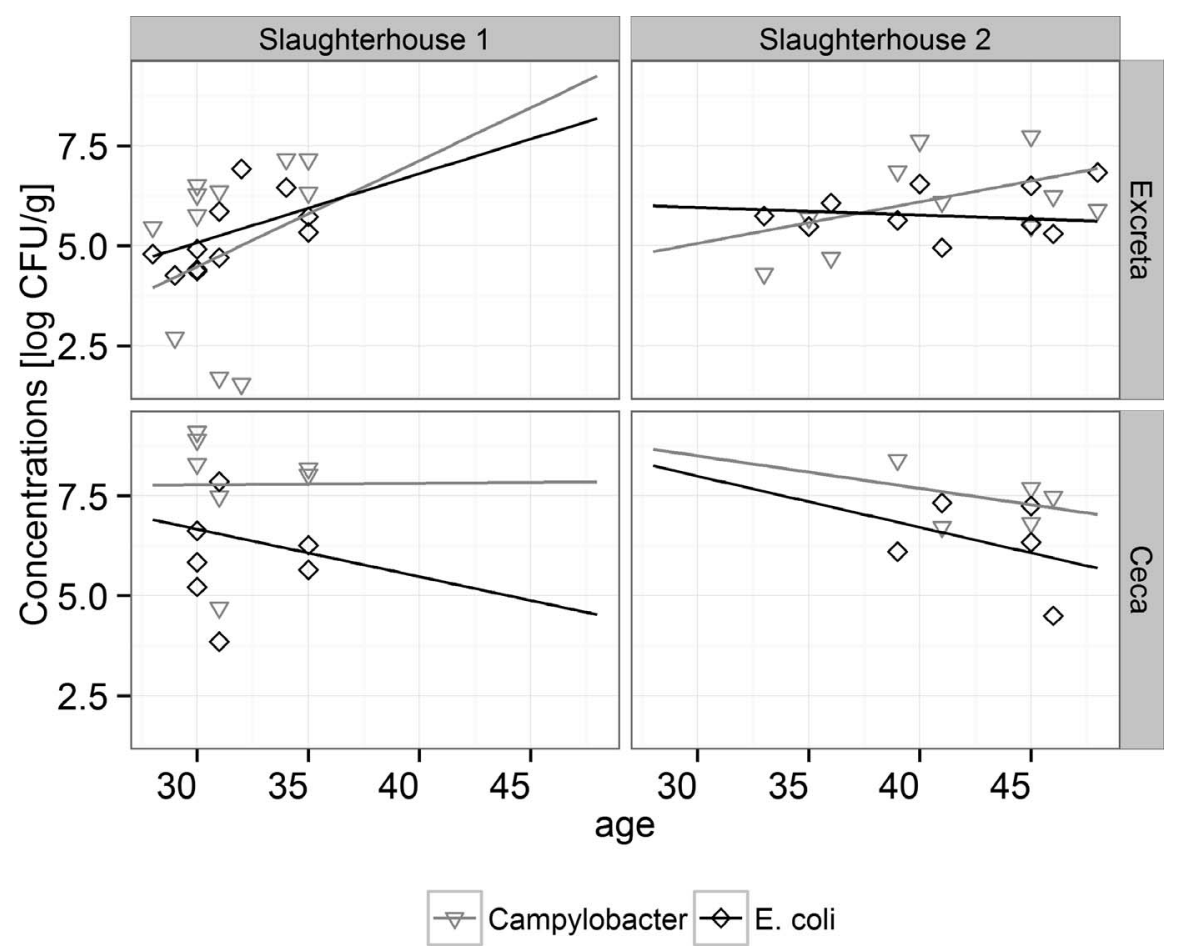

increase in bacterial concentrations after defeathering (Fig. 3 and Table 4). Differences in bacterial concentrations on the exterior and in the excreta of carcasses might explain the different impacts of defeathering on Campylobacter and $E$. coli concentrations observed in our previous study (22). The bacteria present on the carcasses after scalding may be removed with water and feathers during defeathering and replaced by bacteria from leaking excreta. Our experiment on manual defeathering confirms that this could be the case. While eliminating the fecal leakage during manual defeathering, the bacterial concentration on carcasses was not reduced (Fig. 2), which points to the role of concentrations in the exterior of carcasses. Perhaps, this concentration did not decrease because during manual defeathering, the carcasses were not sprayed, as does occur during mechanical defeathering. Spraying water, as well as feathers dropping from the defeathering machines, carried high concentrations of bacteria (Fig. 3), which confirms the removal of Campylobacter and E. coli during defeathering. However, to interpret the bacterial concentrations in the inputs and outputs to the defeathering step require a mechanistic model. Such models help to identify why we observed lower E. coli
FIGURE 2. Comparison of Campylobacter and $\mathrm{E}$. coli concentrations in rinse samples (log CFU per milliliter) from mechanically and manually defeathered carcasses in each slaughterhouse. The length of the box indicates the interquartile range of a sample; the whiskers designate a sample maximum and minimum, and the black dots represent outliers. The bold line in the box indicates the median. The triangles show the Campylobacter concentrations in a particular sample, and diamonds indicate E. coli.
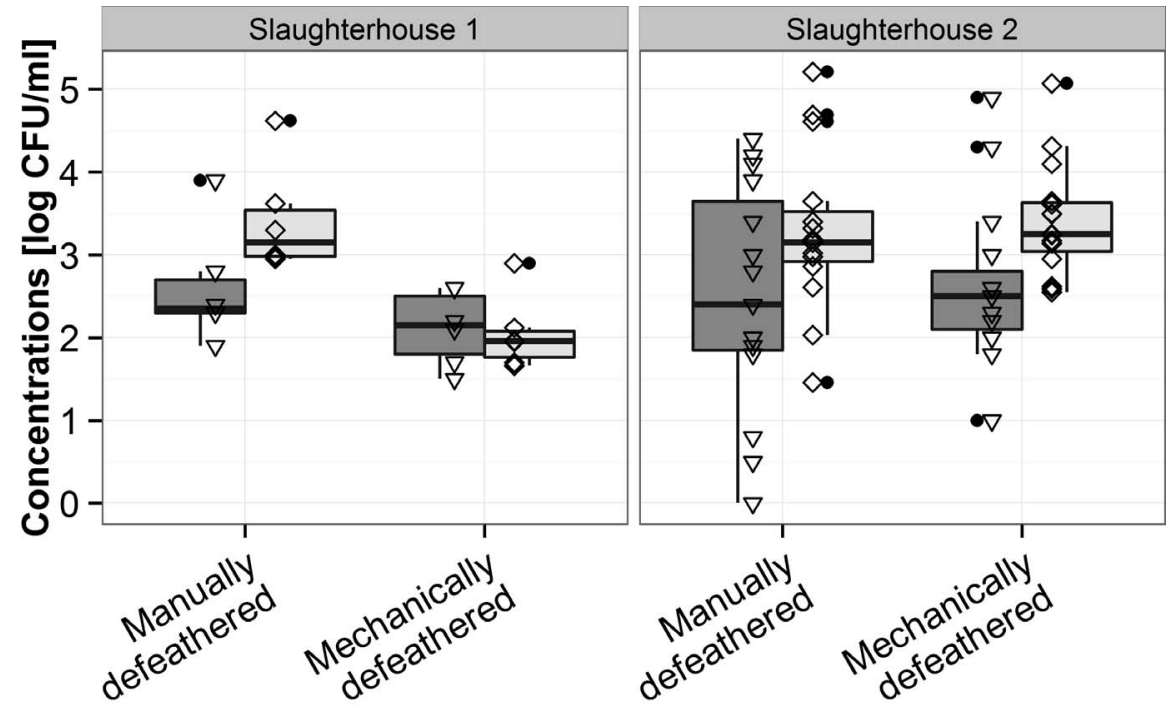

\footnotetext{
$\nabla$ Campylobacter $\diamond$ E. coli

Organism 局 $\begin{aligned} & \text { Campylobacter } \\ & {[\log \mathrm{CFU} / \mathrm{ml}]}\end{aligned}\left[\begin{array}{l}\text { E.coli } \\ {[\log \mathrm{CFU} / \mathrm{ml}]}\end{array}\right.$
} 


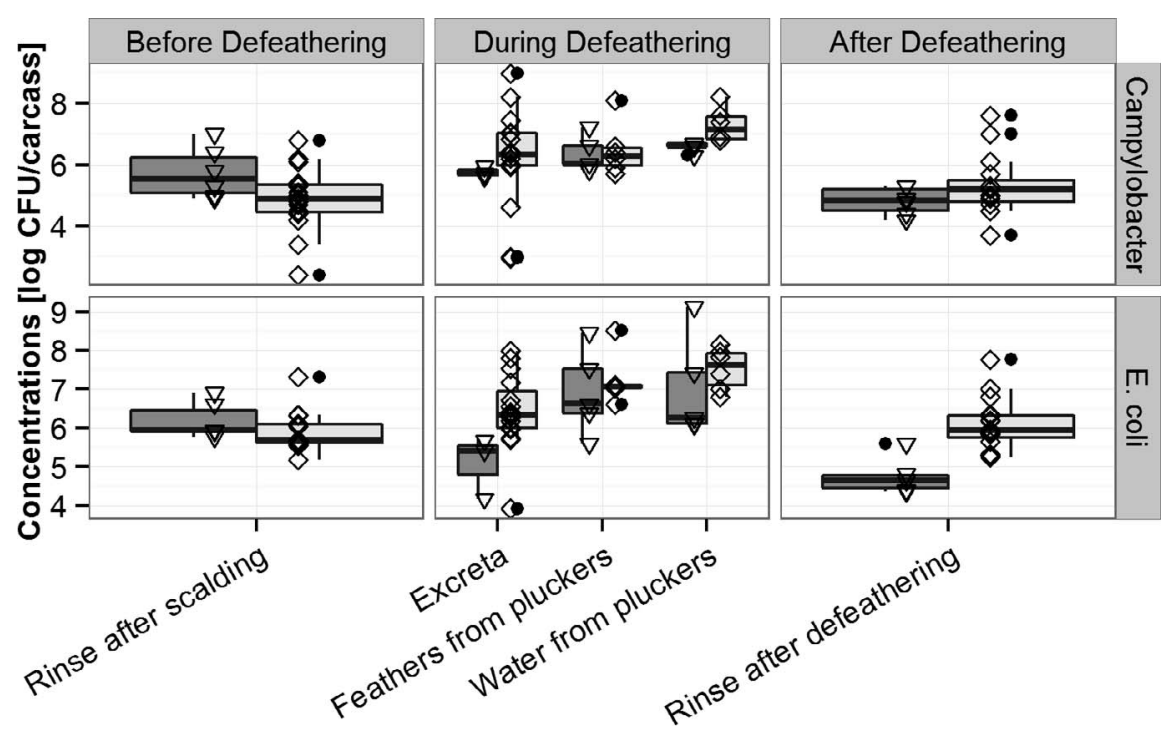

FIGURE 3. Campylobacter and E. coli concentrations before, during, and after defeathering ( $\log C F U$ per carcass). Results for bacterial concentrations are based only on batches $B, C, D, E, F$, and $G$. The triangles indicate the Campylobacter and E. coli concentrations in slaughterhouse 1 and the diamonds in slaughterhouse 2.

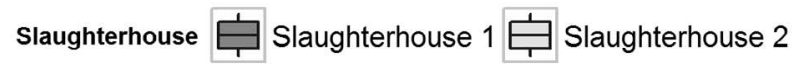

$\nabla$ Slaughterhouse $1 \diamond$ Slaughterhouse 2

concentration on mechanically defeathered carcasses versus manually defeathered only in slaughterhouse 1 .

Poor uniformity of the batch influences leakage during evisceration, because the equipment cannot be adjusted to the individual size of each carcass within a batch $(16,25)$. On the basis of the results of our study, the lower batch uniformity was associated with changes in E. coli concentrations on carcasses during defeathering. Because a poorer uniformity had a different effect in the slaughterhouses studied suggests the potential impact of equipment settings. In general, the equipment should be checked when slaughter of each new batch begins and adjusted depending on the size and weight of the carcasses. With less uniform batches, checking and adjustment of settings could be more frequent. The different effect of heterogenous batches could be due to the food handlers in each slaughterhouse setting equipment differently while processing these batches. These settings potentially affect the fecal leakage, which contributes to an increase in bacterial concentrations on carcasses during defeathering. More uniformity is expected to lead to better equipment performance in every slaughterhouse.
In addition, the association between $E$. coli concentrations during defeathering in slaughterhouse 2 and the remaining feathers also points toward the role played by equipment settings. Looser settings of defeathering machines reduce the effectiveness of the removal of feathers and might reduce pressure on the abdominal area of the carcasses and thus fecal leakage. As a result, bacterial concentrations on carcasses during defeathering might be lower than in the case of tight setting, although tight settings achieve complete removal of feathers.

From the list of explanatory variables (Table 2) evaluated in this study, only a few were statistically associated with the changes in bacterial concentrations during processing in the two slaughterhouses studied. Thus, the variability in changes in bacterial concentrations is still not fully explained. More insight is needed into the contribution of food handlers to bacterial contamination during the processing, as well as the management practices that influence it (20). In addition, this study did not investigate the contribution of farm management, such as the age of houses, architectural differences, or biosecurity

TABLE 4. Comparison of Campylobacter and E. coli concentrations in carcass rinse samples collected before and after defeathering and between carcass rinse samples after scalding and excreta leaking during defeathering ${ }^{a}$

\begin{tabular}{|c|c|c|c|c|c|}
\hline \multirow[b]{2}{*}{ Slaughterhouse } & \multirow[b]{2}{*}{ Organism } & \multicolumn{2}{|c|}{$\begin{array}{l}\text { Concn in excreta minus } \\
\text { concn after scalding (log CFU/carcass) }\end{array}$} & \multicolumn{2}{|c|}{$\begin{array}{l}\text { Concn after defeathering minus } \\
\text { concn after scalding (log CFU/carcass) }\end{array}$} \\
\hline & & Difference & $P$ value & Difference & $P$ value \\
\hline \multirow[t]{2}{*}{1} & Campylobacter & 1.38 & $<0.001$ & 0.01 & 0.99 \\
\hline & E. coli & -0.81 & $<0.001$ & -1.26 & $<0.001$ \\
\hline \multirow[t]{2}{*}{2} & Campylobacter & 1.51 & $<0.001$ & 0.41 & 0.2 \\
\hline & E. coli & -0.1 & 0.96 & -0.52 & 0.002 \\
\hline
\end{tabular}

${ }^{a}$ Results are based on ANOVA and post hoc Tukey honestly significant difference test on batches B, C, D, E, F, and G. 
practices. The age of the houses for example, has been identified as a risk factor for introducing Campylobacter into broiler flocks (19). Such farm management-related factors could potentially explain the differences in Campylobacter concentrations between the batches at the beginning of processing after bleeding.

In conclusion, this study demonstrates that the bacterial concentrations of Campylobacter and E. coli in the intestines of the carcasses are the predominant explanatory variables of carcass contamination because they were associated with Campylobacter and E. coli concentrations at various processing steps. Our findings confirm that control of bacterial concentrations both on the farm and during processing are needed to reduce postchilling carcass contamination. Control during processing, e.g., during defeathering, should be focused on reducing fecal leakage that leads to cross-contamination throughout the processing. The associations determined, however, provide an indication of areas of potential control that should be confirmed by additional studies. As each slaughterhouse is unique, each should individually identify deficiencies in process control and implement measures to improve the processing hygiene. This requires individual slaughterhouses to monitor bacterial concentration along the whole processing line. Further insight is needed to address the contribution of food handlers and management regarding the differences observed between slaughterhouses.

\section{ACKNOWLEDGMENTS}

This study was financed by MEYN Food Processing Technology B. V., Oostzaan, The Netherlands. The authors thank the staff at the slaughter plants for their cooperation and support in the fieldwork, the technical staff and interneess from the laboratory of the Veterinary Public Health Division for their support in the analytical work, and the technology group from MEYN for their support during the fieldwork. The authors also thank Dr. Janet Corry, School of Veterinary Science, University of Bristol, United Kingdom, for assistance with manuscript revision.

\section{REFERENCES}

1. Anonymous. 2006. ISO 10272-2 Microbiology of food and animal feeding stuffs-horizontal method for the detection and enumeration of Campylobacter spp.—part 2: Colony count technique. ISO/TS 10272-2:2006. International Organization for Standardization, Geneva.

2. Anonymous. 2011. Eindrapportage Convenant Campylobacter aanpak pluimveevlees in Nederland. Resultaten van twee jaar monitoring op de Nederlandse vleeskuikenslachterijen. Available at: http://www. nepluvi.nl/dynamic/media/1/documents/Campylobacter/059_ eindrapportage_campylobacter_convenant_2009-2010.pdf. Accessed January 2016.

3. Berrang, M. E., R. Buhr, J. A. Cason, and J. A. Dickens. 2001. Broiler carcass contamination with Campylobacter from feces during defeathering. J. Food Prot. 64:2063-2066.

4. Berrang, M. E., and J. A. Dickens. 2000. Presence and level of Campylobacter on broiler carcasses throughout the processing plant. J. Appl. Poult. Res. 9:43-47.

5. Bilgili, S. 2004. Broiler processing timely information April 2004. Uniformity. Available at: http://poul.auburn.edu/wp-content/uploads/ sites/13/2014/09/wogsapr04.pdf. Accessed January 2016.

6. Bouwknegt, M., A. W. van de Giessen, W. D. C. Dam-Deisz, A. H. Havelaar, N. J. D. Nagelkerke, and A. M. Henken. 2004. Risk factors for the presence of Campylobacter spp. in Dutch broiler flocks. Prev. Vet. Med. 62:35-49.
7. Cason, J. A., M. E. Berrang, R. J. Buhr, and N. A. Cox. 2004. Effect of prechill fecal contamination on numbers of bacteria recovered from broiler chicken carcasses before and after immersion chilling. J. Food Prot. 67:1829-1833.

8. Cibin, V., M. Mancin, K. Pedersen, F. Barrucci, S. Belluco, A. Roccato, F. Cocola, S. Ferrarini, A. Sandri, D. Lau Baggesen, and A. Ricci. 2014. Usefulness of Escherichia coli and Enterobacteriaceae as process hygiene criteria in poultry: experimental study. Available at: www.efsa.europa.eu/publications. Accessed January 2016.

9. Duffy, L. L., P. J. Blackall, R. N. Cobbold, and N. Fegan. 2014. Quantitative effects of in-line operations on Campylobacter and Escherichia coli through two Australian broiler processing plants. Int. J. Food Microbiol. 188:128-134.

10. European Food Safety Authority. 2010. Analysis of the baseline survey on the prevalence of Campylobacter in broiler batches and of Campylobacter and Salmonella on broiler carcasses in the EU, 2008 - part A: Campylobacter and Salmonella prevalence estimates. EFSA J. 8:1503. doi:10.2903/j.efsa.2010.1503.

11. European Food Safety Authority. 2011. Scientific Opinion on Campylobacter in broiler meat production: control options and performance objectives and/or targets at different stages of the food chain. EFSA J. 9:2105. doi:10.2903/j.efsa.2011.2105.

12. European Food Safety Authority. 2012. Scientific Opinion on the public health hazards to be covered by inspection of meat (poultry) EFSA J. 10:2741. doi:10.2903/j.efsa.2012.2741.

13. European Food Safety Authority. 2015. The European Union summary report on trends and sources of zoonoses, zoonotic agents and food-borne outbreaks in 2013. EFSA J. 13:3991. doi:10.2903/j. efsa.2015.3991.

14. Holm, S. 1979. A simple sequentially rejective multiple test procedure. Scand. J. Stat. 6:65-70.

15. Hue, O., S. Le Bouquin, M. Laisney, V. Allain, F. Lalande, I. Petetin, S. Rouxel, S. Quesne, P. Gloaguen, M. Picherot, J. Santolini, G. Salvat, S. Bougeard, and M. Chemaly. 2010. Prevalence of and risk factors for Campylobacter spp. contamination of broiler chicken carcasses at the slaughterhouse. Food Microbiol. 27:992-999.

16. Malher, X., M. Simon, V. Charnay, R. D. des Déserts, A. Lehébel, and C. Belloc. 2011. Factors associated with carcass contamination by Campylobacter at slaughterhouse in cecal-carrier broilers. Int. J. Food Microbiol. 150:8-13

17. Musgrove, M. T., J. A. Cason, D. L. Fletcher, N. J. Stern, N. A. Cox, and J. S. Bailey. 1997. Effect of cloacal plugging on microbial recovery from partially processed broilers. Poult. Sci. 76:530-533.

18. Näther, G., T. Alter, A. Martin, and L. Ellerbroek. 2009. Analysis of risk factors for Campylobacter species infection in broiler flocks. Poult. Sci. 88:1299-1305.

19. Nauta, M. J., C. Van Wagenberg, H. M. Sommer, H. Rosenquist, and P. Van Horne. 2015. Deliverable from the project CamCon Campylobacter control-novel approaches in primary poultry production. Deliverable 4.5.2: Report on major outcomes of WP4. Available at: http://www.camcon-eu.net/wp-content/uploads/2015/05/ D-4.5.2-Report-major-outcomes-WP4.pdf. Accessed April 2016.

20. Pacholewicz, E., S. A. S. Barus, A. Swart, A. H. Havelaar, L. J. A. Lipman, and P. A. Luning. 2016. Influence of food handlers' compliance with procedures of poultry carcasses contamination: a case study concerning evisceration in broiler slaughterhouses. Food Control 68:367-378.

21. Pacholewicz, E., A. Liakopoulos, A. N. Swart, B. G. M. Gortemaker, C. Dierikx, A. H. Havelaar, and H. Schmitt. 2015. Reduction of extended-spectrum- $\beta$-lactamase-and AmpC- $\beta$-lactamase-producing Escherichia coli through processing in two broiler chicken slaughterhouses. Int. J. Food Microbiol. 215:57-63.

22. Pacholewicz, E., A. N. Swart, M. Schipper, B. G. Gortemaker, J. A. Wagenaar, A. H. Havelaar, and L. J. A. Lipman. 2015. A comparison of fluctuations of Campylobacter and Escherichia coli concentrations on broiler chicken carcasses during processing in two slaughterhouses. Int. J. Food Microbiol. 205:119-127.

23. Reich, F., V. Atanassova, E. Haunhorst, and G. Klein. 2008. The effects of Campylobacter numbers in caeca on the contamination of 
broiler carcasses with Campylobacter. Int. J. Food Microbiol. 127:116-120.

24. Rivoal, K., T. Poezevara, S. Quesne, V. Ballan, and M. Chemaly. 2015. Optimization of air chilling process to control Campylobacter contamination on broiler legs. Presented at the 18th International Workshop on Campylobacter, Helicobacter and related organisms, Rotorua, New Zealand, 1-5 November 2015.

25. Rosenquist, H., H. M. Sommer, N. L. Nielsen, and B. B. Christensen. 2006. The effect of slaughter operations on the contamination of chicken carcasses with thermotolerant Campylobacter. Int. J. Food Microbiol. 108:226-232.
26. Swart, A., M. J. Mangen, and A. H. Havelaar. 2013. Microbiological criteria as a decision tool for controlling Campylobacter in the broiler meat chain. Report of Dutch National Institute for Public Health and the Environment (RIVM). Report 330331008. RIVM, Bilthoven, The Netherlands.

27. Williams, M. S., and E. D. Ebel. 2014. Estimating the correlation between concentrations of two species of bacteria with censored microbial testing data. Int. J. Food Microbiol. 175, 1-5.

28. Zweifel, C., D. Althaus, and R. Stephan. 2015. Effects of slaughter operations on the microbiological contamination of broiler carcasses in three abattoirs. Food Control 51:37-42. 